\title{
Sustaining Motivation of Engineering Students in India by Managing their Academic \& Affective Needs
}

\author{
Amit Lathigara ${ }^{1}$, Lipika Gupta ${ }^{2}$, Binu K.G ${ }^{3}$, Veena Kumar ${ }^{4}$ \\ ${ }^{1}$ School of Engineering, RK University, Gujarat, India, amit.lathigara@rku.ac.in \\ ${ }^{2}$ Chitkara University Institute of Engineering and Technology, Chitkara University, Himachal Pradesh, India, \\ lipika.gupta@chitkarauniversity.edu.in \\ ${ }^{3}$ St Joseph Engineering College, Mangalore, India, binuk@sjec.ac.in \\ ${ }^{4}$ University of Maryland Global Campus, USA, veena.kumar@faculty.umgc.edu
}

\begin{abstract}
In India, nearly 1.5 million students enrol in engineering programs in around 4000 colleges. These students come from very diverse demographic, sociocultural and economic backgrounds. Many of them are unable to successfully transition from school to the very demanding environment of engineering education because of poor levels of academic and emotional preparedness. They become demotivated and disengaged which in turn, negatively impacts their academic performance. The objective of this study is to investigate the reasons for demotivation and recommend possible solutions. The study was conducted in three phases using multiple specially designed instruments. In the first phase, Instrument 1 was administered to 349 students to establish the diversity in engineering student population. Then, 79 students with low motivation and academic performance were identified using Instrument II. Personal interviews were conducted using Instrument III with the identified low-performing subjects to get an insight into their learning and emotional needs. Over an entire semester, well-planned interventions were provided to address the identified learning and emotional needs. At the end of the semester, academic performance of the 79 subjects was re-recorded. Due to sudden lockdown and transition to online instruction in the middle of the semester (because of COVID-19), separate data were collected for pre and post lock down periods. Results obtained showed remarkable progress in both pre and post lockdown periods. The paper concludes with a set of concrete recommendations for engineering institutions and faculty for effectively managing student motivation, building confidence and getting them ready for the highly competitive job market.
\end{abstract}

Keywords: Academic preparedness; affective needs; socioeconomic differences; low academic performance

\section{Introduction}

With 4000 engineering institutions enrolling nearly 1.5 million students every year, India is the hub of engineering education in the world. In spite of the fact that engineering education is relatively expensive and threatened by lack of guaranteed employability, most high-school students, along with their parents, consider it to be the dream program of study. At the time of joining, students are full of enthusiasm and confidence but once the program starts, many of them begin to lose motivation and feel disengaged, isolated and neglected. They become demotivated basically because they are unable to cope with the academic and emotional demands of engineering education. This starts a vicious cycle of lack of motivation leading to poor academic performance, which in turn, causes further de-motivation.

\section{Diversity in student population}

While undergraduate classes across the globe are expected to be heterogeneous, in India, this diversity is much more pronounced, especially in engineering institutions. In a typical engineering program class of 45 - 60 students you are likely to find students with very diverse demographic, socio-cultural and economic backgrounds. Each of these students has different reasons, expectations and aspirations for joining the engineering program. India is a vast country and socio-cultural and socio-economic differences deeply impact the students' overall personality in terms of self-efficacy and flexibility for academic and emotional adjustment in the new learning environment. These differences also play an important role in students' attitude towards their studies as well as toward relationship with their faculty and peers. Research shows that there is 'significant relationship between family's socio-economic status and the academic achievement of students (Sirin, 2005; White, 1982).

\section{Research Question:}

The main premise of the study is that if the reasons for demotivation can be identified and addressed early, effective solutions can be put in place to reverse the trend and improve students' academic performance. The paper investigates the question:

To what extent demotivation and disengagement leading to poor academic performance among undergraduate students in engineering programs in India, can be reversed by early detection and response to their academic and emotional needs arising from pronounced socio-cultural and economic differences?

\section{Literature Survey}


The study began with extensive literature survey on different issues related to loss of motivation due to poor transition from a secure, protected learning environment of high school to a more rigorous, competitive and somewhat harsher environment of a college. At the heart of the struggle are the pronounced demographic, socio-cultural and economic differences of the student population that strongly impact their academic and affective preparedness for succeeding in engineering programs.

\section{Impact of Socio-cultural and economic factors}

Literature survey highlights that the academic performance has a direct relationship with the socio-cultural and economic differences among the students. This study attempts to explore this relationship based on their demographic profile, family background, Schooling and command over the English language.

A very insightful article on Socioeconomic Status and Academic Achievement at Secondary Schools in Mogadishu, Somalia (Abdulkadir et al., 2016) confirms that there is a definite relationship between the socio-economic status of students and their academic achievement. This article studied the phenomenon amongst secondary students who are just a bit younger than our subject population. The study found that 'academic achievement had significant positive influence with three independent variables namely, parents' education, parents' occupation and parents' income'. A comparative report on lower secondary students also indicated that socio-economic background significantly influences self-concept and academic achievement of students (Hassan, 2009). Studies also suggest that students from low socioeconomic backgrounds really value a university degree since the qualification has a direct bearing on the earning capacity of the student, and the economic well being of the student's family (Mcghie, 2012; Sommer \& Dumont, 2011). This suggests that students from low socioeconomic backgrounds may be highly motivated to succeed in studies, but are not necessarily adequately prepared to do so (Jama et al., 2009; Van \& Susanna, 2009). A study of higher education Institutes in Malaysia captured the higher education socioeconomic index based on the parental factors and study environment at home (Zainal et al., 2013). This study included factors like parents' income, mother's and father's educational background, availability of internet, personal computer, personal study space etc. It is shown that the students with higher socio-economic scores perform better and are motivated to study in public universities in comparison to the students having lower socio-economic scores. (Farrell et al., 2015) highlighted that the spatial abilities of the students doing STEM (Science Technology, Engineering \& Mathematics) were influenced by first language, socioeconomic status, culture etc. The study was performed on the students from three different cultures and their performance in STEM courses. According to Okioga, the basics have to be strong and clear at high school level for which education plays a major role not only at institution but also at home (Okioga, 2013). Similarly, a study Loeb and Herd conducted a study on underrepresented students in the United States. The study endorsed that first-generation college students, or students from economically disadvantaged family backgrounds had a higher dropout rate and had low motivation (Loeb \& Hurd, 2019). The academic performance of such students was considerably lower than other students. The study states that lower confidence level and self-doubt are the major reasons.

An interesting fact about students' intrinsic and extrinsic motivation is highlighted in a recent study on students in engineering preparatory programs (Gero \& Abraham, 2018). Intrinsic motivation refers to student's own interest to learn engineering while extrinsic motivation is dependent upon two factors: (a) students finding value in pursuing the course (b) students want to appease their parents. The study highlights that in the beginning of the program Intrinsic motivation is high while the extrinsic motivational influences the student's performance at a later stage of the course. In (Korkmaz et al., 2019), a study conducted on the students from the Industrial Engineering Department at Gaziantep Universities, Turkey, showed that there was little to no correlation between the academic achievement of the students and their demographic profile, which contradicts the studies done in other countries including this study.

\section{Lack of Academic Preparedness}

It is a well-known fact that most high-school students, have difficulty transitioning to higher education. Transitioning to STEM programs becomes even more challenging. There is a clear link between students' academic preparedness and their academic performance. Students are highly excited and proud when they begin their journey of engineering education. Fig. 6 shows the reasons why students choose to do engineering. Once the courses start, they are unable to cope with the rigors of the engineering education mainly because they are poorly prepared to follow the courses.

Academic unpreparedness is much more than just the lack of required background knowledge; it is related to how learning is approached. Depending on the type of school attended, most high school students lack critical thinking and problem-solving skills. At school level, the content is narrowly defined, normally limited to one text book (Wats \& K. Wats, 2013). The complexity of test and exams at school level is also fairly low and targeted basically to the lowest levels of Bloom's taxonomy. There is little to no preparation for research and individual thinking.

In a study, (Mcghie, 2012) identified various factors that help in making successful transition from school to university. The study recommends that students should be made responsible for their own learning from start of their 
degree programs. Parents and family should provide them moral support and encouragement throughout the study, and the faculty must encourage, guide and assist them throughout the study.

\section{Lack of proficiency in Spoken English}

All interaction in engineering colleges in India is in English and not having an adequate level of spoken English impedes students' active participation in and outside the class. This deficiency negatively impacts students' motivation and confidence level. Results shared by a study on importance of linguistic capabilities conducted on Iranian medical students confirmed that 'language proficiency in general as well as scientific use could significantly influence academic achievement of medical students in Iran' (Sadeghi et al., 2013). This phenomenon is fully applicable to engineering students in India. The medium of the engineering instruction across the nation is English, while many students complete their entire schooling in the regional language (Figs $3 \& 4$ ). This study reveals that even students from English medium schools are not very confident about their proficiency in spoken English and see this as a major impediment in communicating with the faculty and gaining acceptance with their peers.

\section{Lack of Emotional Preparedness}

According to a report by Jordan Parco Foundation (2015), emotional preparedness may be defined as the ability to take care of oneself, adapt to new environments, control negative emotions or behaviour and build positive relationships (McDonough, 2015). Lack of this competence can lead to a lot of stress amongst engineering students, specially, in first-year students. Typical undergraduate engineering students experience a lot of stress related to i) fear of failure, ii) concern about financial insecurities, and iii) coping with peer-pressure. One of the main reasons for stress is the fear of failure and letting down the parents. The very high incidence of plagiarism in class assignments and exams is related to this stress. The other important stress-inducing factor is the pressure to cover the 'Backlog'. In India, when a student fails a course or gets an Incomplete, he/she accumulates 'Backlog' that needs to be cleared within a prescribed schedule. This is a major source of stress that creates a vicious cycle of struggling to clear backlog and at the same time, performing well in the current courses.

Closely related to the fear of failing is the worry about financial resources. In India, higher education is mostly financed by the family (Fig. 5). Parents often go well beyond their means, at times, to the extent of mortgaging their land or property to finance professional education of their children. According to Mistry et all (2009), perception of family economic stress and personal financial constraints can cause emotional distress/depression in students and impact their academic outcomes.

However, the biggest source of stress is when students feel unaccepted by their peers and the social world of the college. Students who lack such feelings are often characterized as disengaged or alienated (Willms, 2003). It is important for educators to be sensitive to these emotional pressures and help students to effectively balance their Positive Academic Emotions (PAEs) [enjoyment, interest, hope, pride, and relief] and Negative Academic Emotions (NAEs) [anxiety, depression, shame, anger, worry, boredom, and hopelessness]. These are different from negative emotions induced due to factors that are not directly related to studies but have a bearing on academic performance, such as: personal insecurity and complexes arising out of socio-economic, and sociocultural differences. They have a strong impact on student motivation. Several studies point to a strong relationship between emotional preparedness and academic achievement of students (Lei et al., 2018; Valiente et al., 2012).

A great deal of emotional stress is experienced by students who come from rural areas. Amongst these are many first-generation students (first members of a family to go to college). These students have major emotional adjustments to make both at college and at home. On the one hand, there is pressure to conform to peer style (dressing, speaking, choice of music, movies), and on the other, there is worry of offending the parents and relatives for stepping out of their traditionally perceived image. Most first-generation students are painfully aware that "they are less well prepared for college life than are their classmates who come from college-educated families" (Hsiao, 1992).

\section{Research Design and Implementation}

As stated earlier, the study attempts to identify reasons for demotivation leading to disengagement and poor academic performance. The study proposes to research the academic and affective preparedness of students coming from diverse socio-cultural and economic backgrounds.

The study was conducted in three phases using different instruments over a 10-month period (Sept. 2019 to July 2020). Fig. 1 lists out the key events of the study including the work plan and the time line for the three phases.

Research Tools: The following three instruments were designed to collect data for different components of the study: 


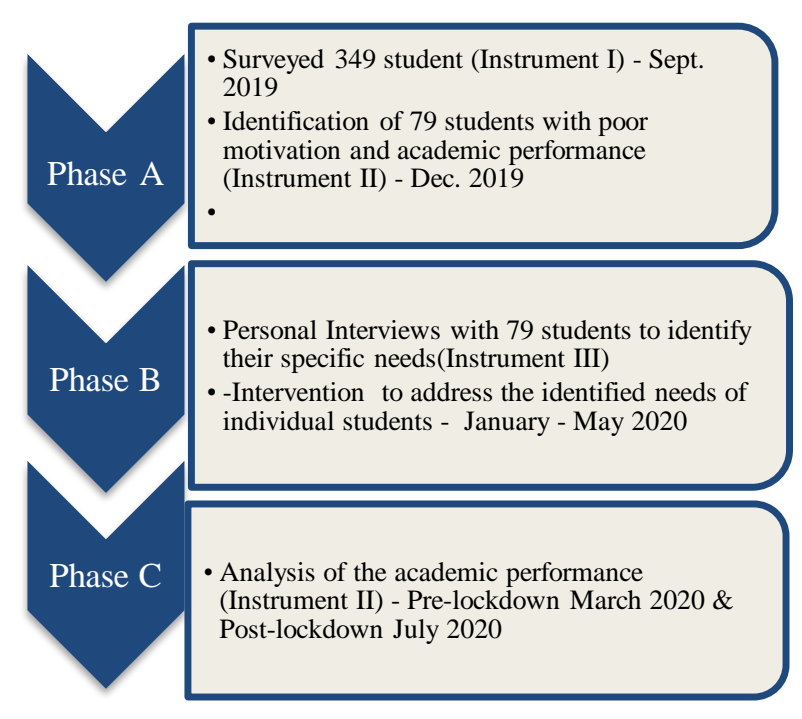

Fig. 1: Research design of the study

Instrument 1 - The objective was to get an overview of the diversity in the profiles of engineering students in India. The responses provided clarity about the vast differences in all aspects related to demographic, socio-cultural, economic backgrounds, students' schooling, the parents educational and professional profiles etc. The survey was composed to cover three main aspects: Section 1 - Socio-economic background (3 questions); Section 2 - Attitude towards Engineering Profession (2 questions); Section 3 - Academic Preparedness (4 questions). The questionnaire was designed to illicit information such as i) the place the students had grown up in (cosmopolitan city, big town, small town, or a village); ii) type of school attended (Schooling in India is extremely diverse ranging from high profile English-medium private schools to regional public school where English is taught as a subject while all other subjects including science are taught in the vernacular language); iii) socio-economic profiles of both parents (educational, professional and financial profiles); and iv) personal assessment of one's own learner profile. The instrument was sent out to 500 students in three colleges located in three different regions of India. 349 Responses were received that were used for this study.

Instrument II - This instrument was designed to identify students with low level of engagement and poor academic performance. This was used in addition to the overall grade of the student. The instrument, designed in the form of a rubric (5 level rating), was used for pre and post evaluation of the subjects. The rubric contained the following evaluation criteria - 1) Attendance; 2). Class Participation, 3) Participation in activities, 4) Timely submission of assignments, and 5) Quality of assignments submitted. Items 1 to 4 provide information about the student's engagement in course work (translated as motivation) while items $3 \& 4$ reflect the academic performance of the student. This instrument was used thrice in the study: (1) pre-intervention, (ii) Post intervention before lockdown due to COVID-19 \& (iii) Post intervention after lockdown.

Instrument III - The objective for designing this instrument was to get insight into the reasons for disengagement/demotivation and consequent poor academic performance so that appropriate intervention can be designed to address the identified reasons. A 19items questionnaire was designed to collect Information about disengagement and consequent poor academic performance. The questionnaire has 4 main sections Reasons for low academic performance (6 options); Reasons for disengagement (5 options); Disappointment with College life (4 options) \& Financial concerns (4 options). Participants were allowed to choose multiple options under each head. The instrument was administered to 79 students in three colleges. The data collected through personal interviews with 79 students was used to design intervention strategies. Table -1 presents the 19-item survey to identify and categorize the reasons for disengagement and poor academic performance.

Table - 1: Instrument - III Reasons for disengagement/demotivation in engineering students

\begin{tabular}{|c|c|c|c|c|}
\hline CATEGORIES & $\begin{array}{l}\text { SL } \\
\text { NO. }\end{array}$ & REASONS & $\begin{array}{l}\text { SL } \\
\text { NO. }\end{array}$ & REASONS \\
\hline \multirow{3}{*}{$\begin{array}{l}\text { ACADEMIC } \\
\text { REASONS }\end{array}$} & 1 & $\begin{array}{l}\text { I cannot } \\
\text { understand the } \\
\text { content being } \\
\text { taught in class }\end{array}$ & 2 & $\begin{array}{l}\text { I am not able } \\
\text { to get any } \\
\text { help from the } \\
\text { teacher }\end{array}$ \\
\hline & 3 & $\begin{array}{l}\text { I feel hesitant to } \\
\text { ask other students } \\
\text { for help }\end{array}$ & 4 & $\begin{array}{l}\text { I do not have } \\
\text { sufficient } \\
\text { background } \\
\text { in science }\end{array}$ \\
\hline & 5 & $\begin{array}{lr}\text { My parents are } \\
\text { not well educated } \\
\text { and } \\
\text { provide } \\
\text { advice }\end{array}$ & 6 & $\begin{array}{l}\text { I do not like } \\
\text { the way } \\
\text { teacher } \\
\text { explains } \\
\text { difficult } \\
\text { concepts }\end{array}$ \\
\hline \multirow{3}{*}{$\begin{array}{l}\text { EMOTIONAL } \\
\text { REASONS }\end{array}$} & 7 & $\begin{array}{l}\text { I am anxious } \\
\text { about my future - } \\
\text { most engineers do } \\
\text { not get jobs }\end{array}$ & 8 & $\begin{array}{l}\text { I am not } \\
\text { happy in this } \\
\text { college }\end{array}$ \\
\hline & 9 & $\begin{array}{l}\text { I find the content } \\
\text { very boring } \\
\text { (never wanted to } \\
\text { be an engineer) }\end{array}$ & 10 & $\begin{array}{l}\text { I think, I am } \\
\text { not as good as } \\
\text { other students } \\
\text { and can never } \\
\text { do well }\end{array}$ \\
\hline & 11 & $\begin{array}{lr}\text { I feel ashamed } \\
\text { that I } & \text { will } \\
\text { disappoint } & \text { my } \\
\text { parents } & \\
\end{array}$ & & \\
\hline \multirow[t]{2}{*}{$\begin{array}{l}\text { SOCIO- } \\
\text { CULTURAL } \\
\text { REASONS }\end{array}$} & 12 & $\begin{array}{l}\text { I find college very } \\
\text { different from } \\
\text { what I expected it } \\
\text { to be }\end{array}$ & 13 & $\begin{array}{l}\text { Most of the } \\
\text { students are } \\
\text { very different, } \\
\text { they dress } \\
\text { differently; } \\
\text { speak } \\
\text { differently }\end{array}$ \\
\hline & 14 & $\begin{array}{l}\text { I feel hesitant to } \\
\text { participate in }\end{array}$ & 15 & $\begin{array}{l}\text { I am from a } \\
\text { rural }\end{array}$ \\
\hline
\end{tabular}




\begin{tabular}{|c|c|c|c|c|}
\hline & & $\begin{array}{l}\text { college activities } \\
\text { because I feel I } \\
\text { cannot speak } \\
\text { English well }\end{array}$ & & $\begin{array}{l}\text { background } \\
\text { and do not } \\
\text { feel } \\
\text { comfortable } \\
\text { with other } \\
\text { students }\end{array}$ \\
\hline \multirow{2}{*}{$\begin{array}{l}\text { ECONOMIC } \\
\text { REASONS }\end{array}$} & 16 & $\begin{array}{l}\text { I feel pressured } \\
\text { that my parents } \\
\text { are under a lot of } \\
\text { financial } \\
\text { constraint because } \\
\text { of me }\end{array}$ & 17 & $\begin{array}{l}\text { I feel most of } \\
\text { the other } \\
\text { students come } \\
\text { from richer } \\
\text { families and I } \\
\text { do not feel } \\
\text { very } \\
\text { comfortable } \\
\text { in their } \\
\text { company }\end{array}$ \\
\hline & 18 & $\begin{array}{l}\text { I feel most of the } \\
\text { other students } \\
\text { come from more } \\
\text { educated families } \\
\text { and I do not feel } \\
\text { very comfortable } \\
\text { in their company }\end{array}$ & 19 & $\begin{array}{l}\text { I am not able } \\
\text { to connect } \\
\text { with most of } \\
\text { the students } \\
\text { because I do } \\
\text { not have } \\
\text { money like } \\
\text { them to spend } \\
\text { in canteen or } \\
\text { restaurants }\end{array}$ \\
\hline
\end{tabular}

\section{Implementation of Intervention:}

The pool of 79 students identified for the study, was classified into three different categories - i) needing academic support; ii) needing affective support, and iii) needing both academic and affective support. As expected, there was a lot of overlap and the following nine strategies were implemented to support the 79 identified subjects. (Table-2).

Table - 2: Strategies for Intervention

\begin{tabular}{|l|l|}
\hline SL NO & STRATEGIES \\
\hline $\mathbf{1}$ & $\begin{array}{l}\text { Profile and data about their existing academic } \\
\text { performance of the 79 subjects was shared with } \\
\text { the concerned course faculty. }\end{array}$ \\
\hline $\mathbf{3}$ & $\begin{array}{l}\text { Instructors were requested to give additional } \\
\text { office hours to these students (individual or in } \\
\text { small groups) }\end{array}$ \\
\hline $\mathbf{4}$ & $\begin{array}{l}\text { Contact was established with the mentors of each } \\
\text { subject and objectives of the study and plans for } \\
\text { intervention were shared with them. They were } \\
\text { requested to log each meeting with the subjects. }\end{array}$ \\
\hline $\mathbf{5}$ & $\begin{array}{l}\text { Instructors were asked to keep a record of the } \\
\text { subjects' participation (frequency and quality) in } \\
\text { their classes and assign them lead roles wherever } \\
\text { possible. }\end{array}$ \\
\hline $\mathbf{6}$ & $\begin{array}{l}\text { For subjects needing only academic support, } \\
\text { instructors were requested to start with assigning } \\
\text { less complex learning tasks homework/team } \\
\text { assignments so that they can feel confident about } \\
\text { managing the course content. The complexity of } \\
\text { the learning tasks and assignments was to be } \\
\text { increased progressively. }\end{array}$ \\
\hline $\begin{array}{l}\text { Faculty was asked to appoint student buddies for } \\
\text { each subject for one-on-one tutoring/personal } \\
\text { time to discuss more } \\
\text { timplex }\end{array}$ \\
\hline
\end{tabular}

\begin{tabular}{|l|l|}
\hline & concepts/assignments. \\
\hline $\mathbf{7}$ & $\begin{array}{l}\text { To support students with 'Incomplete' grades } \\
\text { (backlog), subject experts and mentors were } \\
\text { requested to work with them to organize their } \\
\text { preparation in terms of schedule and learning } \\
\text { materials for revision and preparation for the } \\
\text { make-up exams. }\end{array}$ \\
\hline $\mathbf{8}$ & $\begin{array}{l}\text { Subjects from first year were assigned a student } \\
\text { volunteer 'buddy' for helping with the adjustment } \\
\text { process, especially if the student is in the college } \\
\text { hostel. }\end{array}$ \\
\hline $\mathbf{9}$ & $\begin{array}{l}\text { Students needing help in written and/or spoken } \\
\text { English were identified and attached to a } \\
\text { faculty/senior student from the English } \\
\text { department. }\end{array}$ \\
\hline
\end{tabular}

\section{Results and Discussion}

The data obtained through the research tools are presented and discussed in this section. Inferences are made and discussed regarding the impact of interventions in dealing with demotivation and poor academic performance of students.

Instrument - I enables a better understanding of the diversity in Indian engineering colleges. It was administered to 500 students from three different colleges located in three different regions of India. Responses were received from 349 engineering students. The following results help to bring out the pronounced diversity in engineering education in India.

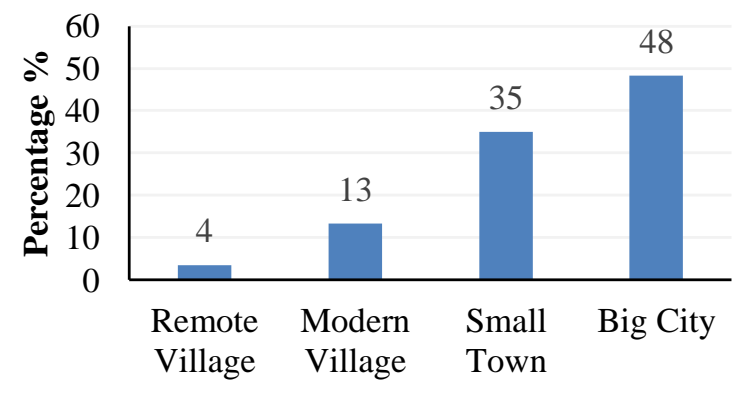

Figure - 2: Demographic Profiles

The demographic profiles of students studying in the three institutions (Fig. 2) shows that $52 \%$ of the student population surveyed are from small towns, modern villages and remote villages. The remaining $48 \%$ students are from cities. These results are an indicator of the pronounced demographic diversity in Indian engineering colleges. Clearly, the learning needs of this diverse population in the engineering classrooms cannot be addressed successfully by using a single homogeneous approach for delivering instruction.

Another factor impacting individual differences is the type of school attended by the students._Teaching in 
schools varies a great deal in India. Fig. 3 presents the variation in the schools attended by the surveyed students. The result reveals a significantly higher percentage $(73 \%)$ of engineering students as having received schooling from Private English Medium Schools.

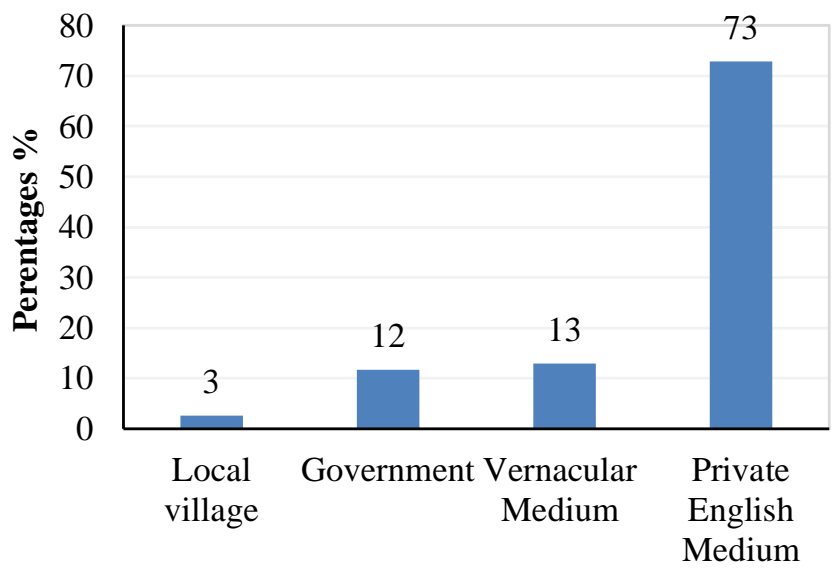

Figure - 3: Variation in Schooling

However, further analysis also reveals that, despite education in English Medium Schools, most students lack confidence and proficiency in spoken English. It is observed from Fig. 4 that $63 \%$ of students possess low or average competency in spoken English. This is an important factor from the perspective of student participation in classes and influences their comprehension and overall educational experience.

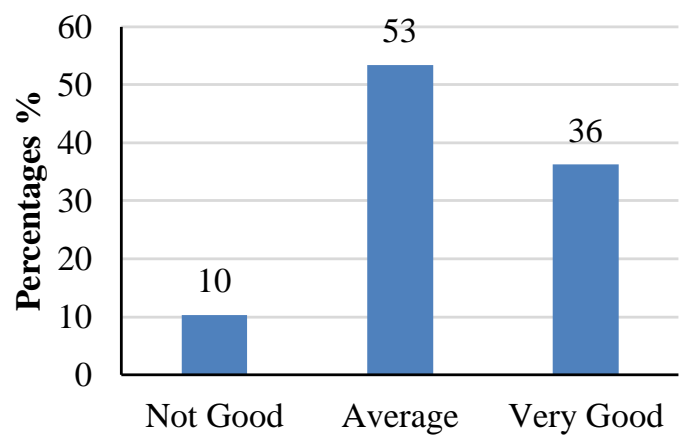

Figure - 4: Level of Spoken English

The socio-economic profiles of engineering students, obtained through Instrument $-\mathrm{I}$, is also analyzed in terms of the financial pressures felt by the students.

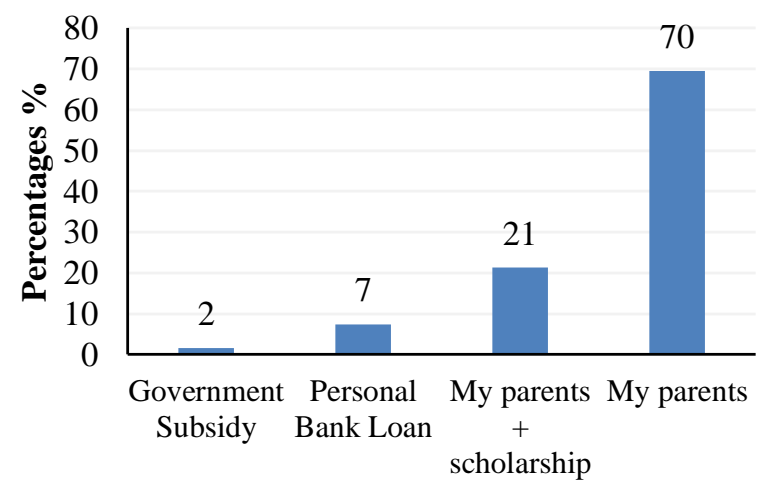

Figure - 5: Modes of financial support

Fig. 5 shows that financial support for $70 \%$ of engineering students comes exclusively from their parents. Another $21 \%$ receives additional support in the form of scholarships. This financial dependency and the fear of financial burden on the parents are significant factors that influence the emotional well being of the students. These emotional factors were closely examined using Instrument -3 and the results are discussed later in this section.

One important perception most commonly shared by the faculty and administration is that students get demotivated because they do not really want to study engineering and are pushed by their parents to join the programs. This is often used as an excuse for poor academic performance of the students. This is clearly negated by the results of the survey (presented in Fig. 6), which shows only $13 \%$ of the students confirm parental pressures for joining engineering studies. This means that in a class of 40-45 students, there are no more than 4-5 students who may fall in this category. The remaining $87 \%$ have given very good reasons for choosing engineering as their career.

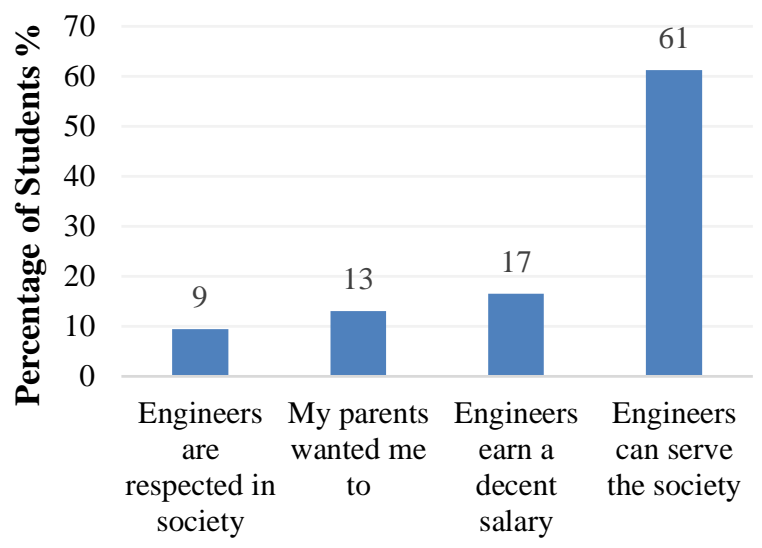

Figure - 6: Purpose of Studying Engineering 
The above results from analysis of Instrument - I, broadly indicates the diversity in engineering education and the challenges faced by the students. The next step was to identify the student sample for interventions. This was achieved using Instrument - II, which recorded the performance of students on key indicators presented in Table - 3. Based on the analysis of Instrument - II, a sample of 79 students were selected for implementing the interventions. The student sample was formed based on the equitable regional spread and demonstrated poor to average performances. The overall performance grades of the selected students before interventions and after interventions are shown in Fig. 7. A closer observation of Fig. 7 reveals the absence of any student with above average $(>60 \%)$ performance, before interventions. Also, a significant percentage of students exhibited below average $(40 \%$ to $50 \%)$ and poor $(<40 \%)$ performances. Fig. 6 also compares the pre-intervention performance grades of the students' sample with their post-intervention grades. It is quite evident from the analysis that the overall performance of the students has considerably improved postinterventions. Fig. 7 reveals that eleven students have moved up to above average $(>60 \%)$ performance and thirteen students have moved up to average (50\% to $60 \%$ ). A proportionate decrease in poor and below average performance is also visible. This result validates the interventions and is in line with the hypothesis that managing individual differences in engineering students can improve their learning experiences. This is further discussed as part of Figs. 8, 9, and 10.

Table - 3: Pre-Intervention Data from Instrument - II

\begin{tabular}{|c|l|c|}
\hline SL NO & CRITERIA & $\begin{array}{l}\text { PERCENTAGE } \\
\text { SCORES }\end{array}$ \\
\hline $\mathbf{1}$ & Attendance in Class & 51 \\
\hline $\mathbf{3}$ & $\begin{array}{l}\text { Attendance in Mentor } \\
\text { Sessions }\end{array}$ & $\begin{array}{l}\text { Alass Participation - } \\
\text { to questions in class }\end{array}$ \\
\hline $\mathbf{4}$ & $\begin{array}{l}\text { Participation in class } \\
\text { activities (in-class } \\
\text { and outside) }\end{array}$ & 31 \\
\hline $\mathbf{5}$ & $\begin{array}{l}\text { Timely Submission } \\
\text { of Assignment }\end{array}$ \\
\hline $\mathbf{6}$ & $\begin{array}{l}\text { Quality of } \\
\text { Assignments }\end{array}$ \\
\hline
\end{tabular}

The total scores in Table - 3 indicate below par performance, before interventions, of the students' sample in all six performance indicators, with comparatively lower scores, in Class Participation - Asking and Responding to Questions in Class, Participation in class activities (inclass and outside), and Quality of Assignment.

\section{Figure 7: Overall Performance of Students Sample before and after Interventions}

To closely understand the reasons for demotivation and disengagement with the course work, Instrument -III was designed and floated. Data from Instrument - III strongly indicates the presence of negative emotions in students due to personal insecurities. These insecurities come from the unattended individual differences that interfere with the smooth transition to higher order learning environment.

The average presence of nineteen reasons of demotivation and poor academic performance, listed in Table -1 and studied using Instrument - III, across the students' population surveyed, is presented in Fig. 8.

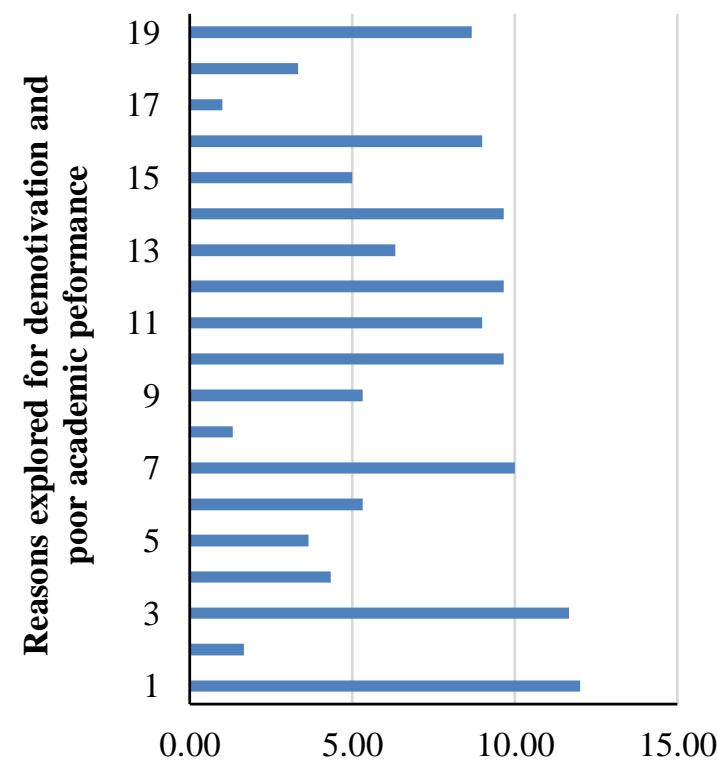

Figure - 8: Average presence of reasons for demotivation and poor academic performance across the surveyed population

Fig. 8 indicates an even spread in the reasons for demotivation and poor academic performance being explored in this study. A closer inspection of individual categories reveals that, difficulty in understanding the contents discussed in class and hesitation in seeking peer help are the most influential academic reasons. It is also observed that while not being able to get help from the teacher is the least impactful academic reason, dissatisfaction with the teaching methods have comparatively higher occurrences. Emotional reasons find strong presence in the population, with anxiety about job opportunities and lower self-esteem having higher occurrences. Among the socio-cultural reasons, two factors that stand out are: dissatisfaction with educational experiences in the college and lack of proficiency in communicating in the English language. With regard to economic reasons, it is observed that 
financial burden on parents and difference in economic standing among peers hold more impact. It is also observed that, some of the impactful reasons are outside the purview of academics and hence remain unmanaged and unnoticed by educators. The regional spread in the factors for demotivation and poor academic performance was analyzed and is presented in Fig. 9. The graph_reveals the significant diversity in categories of reasons influencing demotivation and poor academic performance of students. This observation along with the regional spread in the institutions participating in this study, validates the influence of demographic differences on the educational patterns of engineering students within India. While institutions 1 and 2 show an equal spread in factors, institution 3 shows a higher impact of Socio - Cultural reasons for demotivation and poor academic performance. Interestingly, institution 3 is also least impacted by economic considerations.

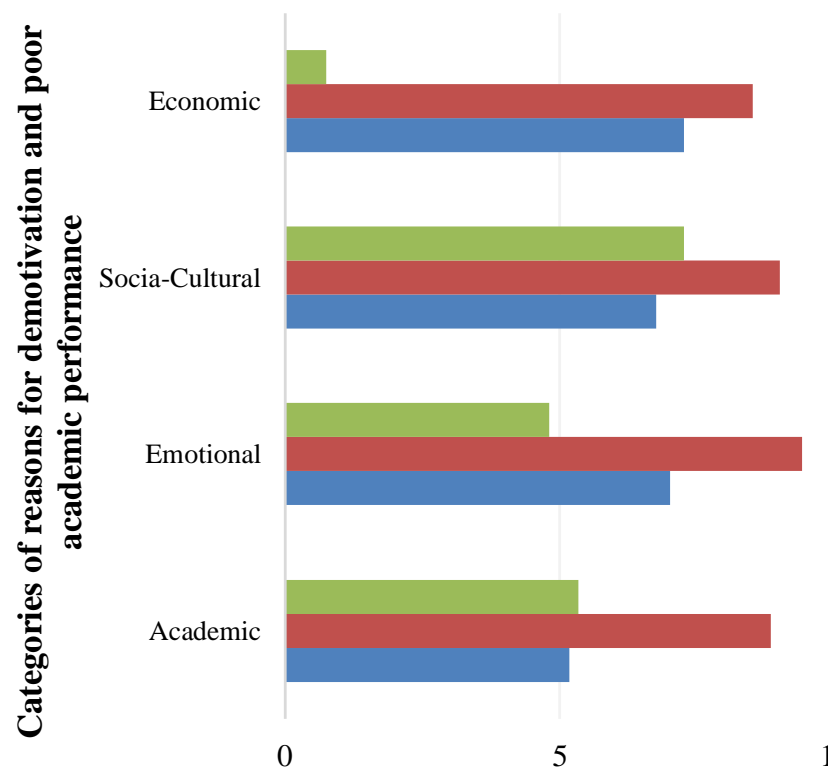

Average Scores

Institution - 3 $\quad$ Institution - 2 $\quad$ Institution - 1
Results of post-intervention data reveal an average improvement of $46 \%$ in the performance indicators for the considered students' sample. This indicates the overall effectiveness of the intervention strategies described in Table -2 . The impact of the interventions is further investigated by further analyzing the improvement in individual performance indicator. Factor wise improvement is presented in Fig. 11. It is observed in Fig. 11 that consistent improvement is reflected in all considered performance indicators. An average improvement of $32 \%$ was observed across all performance indicators.

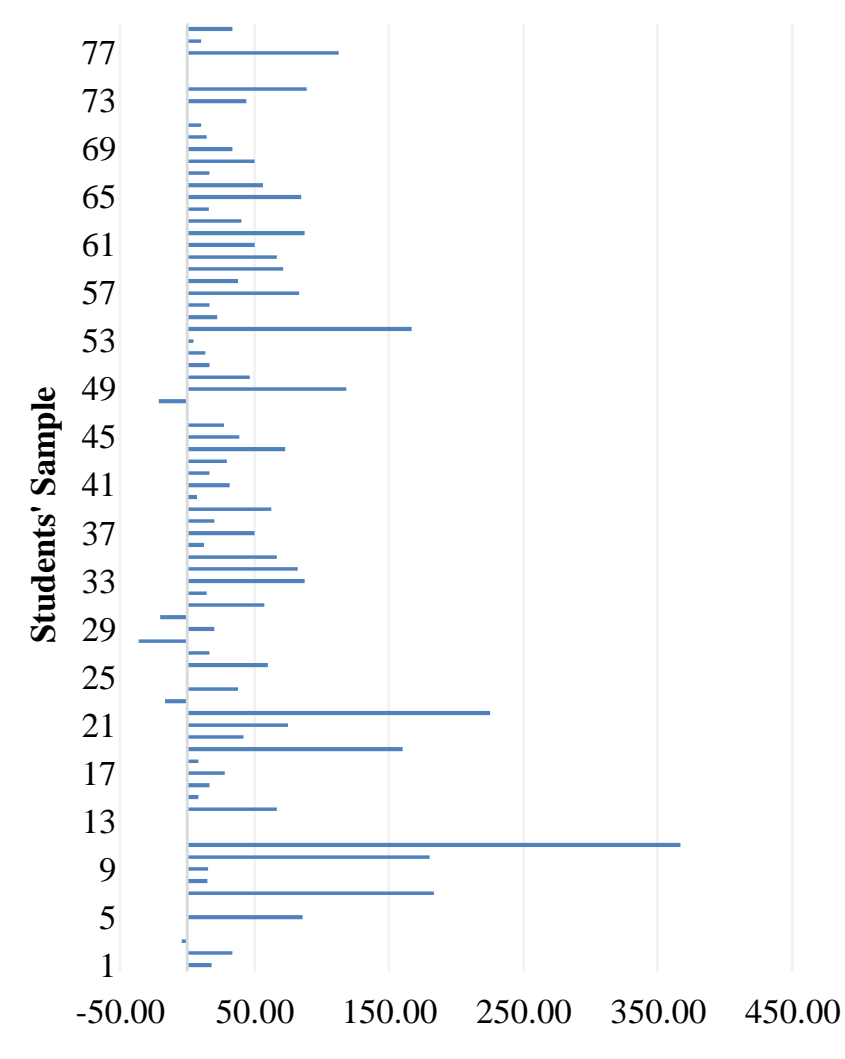

Figure - 10: Percentage improvement in Students' Sample post - intervention 


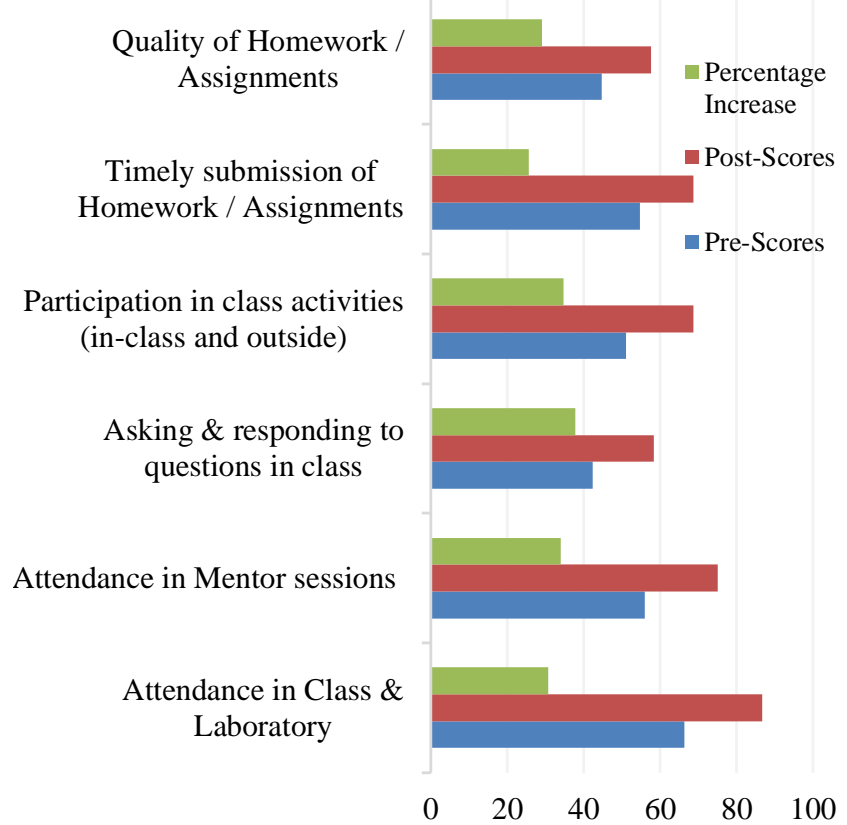

\section{Figure - 11: Improvement in individual performance} indicator

Closer observation reveals that the highest observable improvement is in asking and responding to questions in Class $(38 \%)$ and the lowest improvement is observed for timely submission of assignments (26). These results indicate that the interventions were particularly impactful in managing the confidence levels of students, which enhanced their classroom interactions.

\section{Observations based on data obtained post lockdown due to COVID pandemic:}

Modifications to the data collection and analysis had to be made because of the sudden transition to online teaching during the middle of the semester due to COVID-19 situation. Data regarding subjects' academic performance were thus collected in two different sets. The first set of data reflected subject's academic performance after intervention before the lock down (Dec. 2019 - mid-March, 2020), while the second set represents the academic performance of the subjects' post lockdown (mid-March July 2020)

The results claimed in this paper are based on ONLY the first set of data (pre-lock down) because it is based on the regular mode of instruction. The decision to not include the second set of data is based on the possible lack of reliability because of two important realities: i) different levels of network availability and competency of managing online delivery of courses and activities, and ii) different format of evaluation. These differences render the data unreliable.
However, the second set of data (post lockdown) revealed two very interesting facts directly related to the study. First, the subjects found the anonymity of online medium for interacting with their faculty, mentors and buddies much more effective, and second, their engagement and performance actually improved more than in prelockdown period of the semester.

\section{Conclusions}

The study brought out some very clear indicators that can lead to student demotivation and disengagement in engineering students leading to poor academic performance. Findings of the study confirm that student engagement and academic performance can be enhanced if the academic and affective needs of the students are identified early and addressed promptly. Timely dissemination of important information regarding the challenges and joys of college education must be shared at an early stage. The incoming students must be made aware of the major differences in the overall learning environment between the school and the engineering colleges. They must be mentally prepared for the course delivery mode, the type of activities (in and out of class), the format of assessment and the performance expectations in engineering programs. Some input on best practices and effective study skills must be provided. Most important of all, they must be assured of the full support in both academic and affective domains. At the same time, all essential information must be provided to course faculty and mentors must be provided

\section{Recommendations}

To counter this serious problem, all stakeholders - the institute, the departments, the faculty and the students need to pitch in and work together. Based on the findings of the study, the following recommendations are proposed for the Institutions and the faculty:

\section{Role of the Institutions:}

1. Sharing data about diversity - A proper system needs to be put in place to record each new entrant's demographic, socio-cultural and economic background. A list of the potential 'vulnerable' students needing academic or emotional hand-holding should be created and shared with the concerned departments and the course faculty so that the vulnerable students can be observed and supported right from the beginning.

2. Student-centric Orientation Program - Most engineering colleges have an orientation program that needs to be more student-centric. The orientation program must have clear objectives that include i) making the transition from school to college easy, enjoyable and a matter of pride, ii) explain how the 
institute will help them cope with the demands of the academic up-gradation and iii) emotional adjustment to the new learning environment. Special small-group sessions with senior students should be organized to promote bonding and building a sense of community. Short workshops on topics such as 'How to succeed in engineering programs', 'Participating in collaborative projects'; 'Making the most of Student Services', 'Using the library' etc. can be included.

3. Modifications to the existing mentoring system: Mentoring programs in engineering colleges are generally set-up in a way that each faculty is assigned $25-30$ students to mentor. Normally, mentoring sessions are held in groups where the at-risk students are very reluctant to share their problems. What they need is one-on-one interaction with the faculty or peers-tutors. This was confirmed by the results obtained in the post-COVID segment of the semester because most help was provided online and the privacy made them feel more comfortable.

4. Technology support - With the increased use of technology in teaching, the Institutions must ensure that all students are adequately equipped with digital tools and networking facilities. Faculty and students who live in rural or remote areas where network connectivity is a recognized problem, the institutes must provide pre-paid dongles and data packages for free, or at a highly subsidized rate. Sicpinstitution should tie up with a financial agency and/or a vendor to facilitate easy purchase of desktops, laptops, smart phones and data packages.

5. Student support services - This should be an important priority for all engineering institutions. Support must be arranged to meet both academic and affective needs. If the institute has a Teaching Learning Centre, student services can be located there. It is time for engineering colleges in India to start the practice of hiring senior undergraduate or graduate students from with-in the institution to manage the student support services. Senior students can competently support both the academic and affective needs. The most effective support system can be built on the lines of a mini call centre by enrolling senior undergraduate or graduate students as tutors paid a per-hour remuneration. Support can be provided face-to face, via phone and/or e-mail during or after college hours. This will be a win-win situation for everyone. The student -tutors, In addition to making some money, get an opportunity to develop real world skills, the institution is able to provide high quality support service at a nominal cost, and the students learn from their peers in a more relaxed and joyful manner, This format for support can be specially valuable for first year students. Ellen Jansen and Jacques Meer state that student's preparedness plays a crucial role in the success of first year students (Jansen \& van der Meer, 2012). It is recommended to have separate pedagogical practices in first-year that will help students to develop their academic skills suited for higher education Student-tutors can be very effective in helping needy students develop competency and confidence in speaking English.

\section{Role of the Engineering Faculty:}

1. Awareness about student profiles - engineering classes are typically very large and diverse. It will be very helpful if the course faculty is provided detailed information about their students' demographic, socio-cultural and economic backgrounds for early detection of vulnerable students who are likely to need support.

2. Responsibility for keeping students engaged and motivated - Faculty must be made aware that meeting the affective needs of their students and keeping them motivated is also an important part of their responsibility. Joseph Lowman, in his very insightful 2D model of Effective Teaching (1995) emphasizes that two main dimensions of effective college teaching are building interpersonal rapport and intellectual excitement. Another study confirms that teacher-student engagement is most effective for students at greater risk of academic difficulties (Bergin \& Bergin, 2009; Faircloth \& Hamm, 2005). Faculty may be provided training in managing this aspect of their responsibility.

\section{Future Work}

Research in the area of sustaining student engagement and motivation to improve the academic performance of engineering students in India, was found to be very relevant and rewarding. This effort needs to be taken forward to further study the academic and affective needs of students in different years of the engineering programs. It is clear that students in each year of the engineering program experience a different set of complexities and stresses. Further research is needed to identify these complexities and stresses, and develop strategies and tools for meeting the specific needs of students in different years ( $1 \mathrm{st}, 2^{\text {nd }}, 3^{\text {rd }} \& 4^{\text {th }}$ year), so that the overall standard of engineering education in India can be taken to the next level.

\section{References}

Abdulkadir, M. D., Mohamed Omar, M., \& Abdullahi Aden, M. (2016). Socioeconomic Status and Academic Achievement at Secondary Schools in MogadishuSomalia. International Encyclopedia of the Social \& 
Behavioral Sciences, November, 924-930. https://doi.org/10.1016/B978-0-08-097086-8.92141-X Bergin, C., \& Bergin, D. (2009). Attachment in the Classroom. In Educational Psychology Review. https://doi.org/10.1007/s10648-009-9104-0

Faircloth, B. S., \& Hamm, J. V. (2005). Sense of belonging among high school students representing 4 ethnic groups. Journal of Youth and Adolescence. https://doi.org/10.1007/s10964-005-5752-7

Farrell, S., Duffy, G., \& Bowe, B. (2015). A cross-cultural exploration of spatial visualisation abilities of first year STEM students: Students from Gulf States and Ireland. Proceedings of 2015 International Conference on Interactive Collaborative Learning, ICL 2015, September, 922-926. https://doi.org/10.1109/ICL.2015.7318150

Gero, A., \& Abraham, G. (2018). Students' motivation and academic achievement: The case of an engineering preparatory program. International Journal of Engineering Education, 34(3), 1013-1024.

Hassan, J. E. (2009). Parents' socioeconomic status and children's academic performance. http://reassess.no/asset/3827/1/3827_1.pdf

Hsiao, K. (1992). First-Generation College Students . ERIC Digest . ERIC Clearinghouse for Junior Colleges. Jama, M., Mapesela, M., \& Beylefeld, A. (2009).

Theoretical perspectives on factors affecting the academic performance of students. South African Journal of Higher Education. https://doi.org/10.4314/sajhe.v22i5.42919 Jansen, E. P. W. A., \& van der Meer, J. (2012). Ready for university? A cross-national study of students' perceived preparedness for university. Australian Educational Researcher. https://doi.org/10.1007/s13384-011-0044-6 Korkmaz, I. H., Özceylan, A., \& Özceylan, E. (2019). Investigating the academic success of industrial engineering students in terms of various variables.

Procedia Computer Science, 158, 9-18.

https://doi.org/10.1016/j.procs.2019.09.022

Lei, H., Cui, Y., \& Chiu, M. M. (2018). The relationship between teacher support and students' academic emotions: A meta-analysis. In Frontiers in Psychology. https://doi.org/10.3389/fpsyg.2017.02288

Loeb, E., \& Hurd, N. M. (2019). Subjective Social Status, Perceived Academic Competence, and Academic Achievement Among Underrepresented Students. Journal of College Student Retention: Research, Theory and Practice, 21(2), 150-165.

https://doi.org/10.1177/1521025117696821

Lowman, Joseph (1995) Mastering the Technique of Teaching, Josey Bass, San Francisco, USA McDonough, M. (2015). Students Who Feel Emotionally Unprepared for College More Likely to Report Poor Academic Performance and Negative College Experience. https://www.jedfoundation.org/first-year-collegeexperience-release/

Mcghie, V. F. (2012). Factors impacting on first-Year students' academic progress at a South African University. Dissertation of Stellenbosch University.
Mistry, R. S., Benner, A. D., Tan, C. S., \& Kim, S. Y. (2009). Family Economic Stress and Academic WellBeing Among Chinese-American Youth: The Influence of Adolescents' Perceptions of Economic Strain. Journal of Family Psychology. https://doi.org/10.1037/a0015403 Okioga, C. K. (2013). The Impact of Students' Socio economic Background on Academic Performance in Universities, a Case of Students in Kisii University College. American International Journal of Social Science.

Sadeghi, B., Kashanian, N. M., Maleki, A., \& Haghdoost, A. (2013). English language proficiency as a predictor of academic achievement among medical students in Iran.

Theory and Practice in Language Studies.

https://doi.org/10.4304/tpls.3.12.2315-2321

Sirin, S. R. (2005). Socioeconomic status and academic achievement: A meta-analytic review of research. In Review of Educational Research.

https://doi.org/10.3102/00346543075003417

Sommer, M., \& Dumont, K. (2011). Psychosocial factors predicting academic performance of students at a historically disadvantaged university. South African Journal of Psychology.

https://doi.org/10.1177/008124631104100312

Valiente, C., Swanson, J., \& Eisenberg, N. (2012).

Linking Students' Emotions and Academic Achievement: When and Why Emotions Matter. In Child Development Perspectives. https://doi.org/10.1111/j.1750-

8606.2011.00192.x

Van, H., \& Susanna, M. (2009). Providing and managing student development and support in higher education in a developing country [University of Pretoria].

https://repository.up.ac.za/handle/2263/26492

Wats, M., \& K. Wats, R. (2013). Enhancing Quality of Higher Education through Comprehensive Continuous Evaluation. International Journal for Cross-Disciplinary Subjects in Education.

https://doi.org/10.20533/ijcdse.2042.6364.2013.0165

White, K. R. (1982). The relation between socioeconomic status and academic achievement. Psychological Bulletin. https://doi.org/10.1037/0033-2909.91.3.461

Willms, J. D. (2003). Student engagement at school: A sense of belonging and participation. OECD Retrieved from Www Pisa Oecd Org on March. https://doi.org/10.1787/19963777

Zainal, N. R., Mohd Aminuddin, Z., \& Zainol, M. S. (2013). Higher Education Socioeconomic Index and the socioeconomic composition of student population in public and private higher education institutions. BEIAC 2013 - 2013 IEEE Business Engineering and Industrial Applications Colloquium, 745-749. https://doi.org/10.1109/BEIAC.2013.6560232 